\title{
PENGARUH KONSELING KELOMPOK DENGAN PENDEKATAN BEHAVIORAL TEKNIK POSITIVE REINFORCEMENT TERHADAP PENURUNAN PELANGGARAN TATA TERTIB SISWA KELAS VIII SMP AL-IRSYAD BANYUWANGI
}

\author{
Leza Sukriyah $^{1)}$, Harwanti Noviandari ${ }^{2}$ \\ Fakultas Keguruan dan Ilmu Pendidikan, Universitas PGRI Banyuwangi \\ Email : leza1517@gmail.com ${ }^{1}$ \\ Email : hnoviandari83@gmail.com ${ }^{2}$
}

\begin{abstract}
Abstrak
Tata tertib sekolah ialah ketentuan-ketentuan yang mengatur kehidupan sekolah seharihari dan mengandung sanksi terhadap pelanggarannya, namun masih banyak murid yang melanggar tata tertib sekolah, untuk mengatasi masalah tersebut, diperlukan strategi yang tepat, salah satunya dengan melalui metode konseling. Tujuan utama penelitian ini adalah untuk menguji apakah konseling kelompok dengan pendekatan behavioral teknik positive reinforcement berpengaruh untuk menurunkan tingkat pelanggaran tata tertib siswa kelas VIII di SMP Al-Irsyad Banyuwangi. Metode yang digunakan dalam penelitian ini adalah desain eksperimen dengan menggunakan rancangan control group Pretest and Posttest design. Sampel penelitian sebanyak 20 orang siswa yang sering melanggar tata tertib sekolah. Sampel ditentukan dengan teknik purposive sampling. Dalam penelitian ini analisis data menggunakan analisis data statistik (kuantitatif).
\end{abstract}

Kata Kunci: positive reinforcement, tata tertib.

\begin{abstract}
School rules are the rules that govern the daily life of the school and are subject to sanctions for violations, but there are still many students who violate school rules, to overcome the problem, appropriate strategies are needed, one of them is through counseling method. The main purpose of this research is to test whether group counseling with behavioral approach of positive reinforcement technique has an effect to decrease the level of violation of class VIII student at SMP Al-Irsyad Banyuwangi. The method used in this research is experimental design using control group design Pretest and Posttest design. The sample of research is 20 students who often violate school rules. The sample is determined by purposive sampling technique. In this study data analysis using statistical data analysis (quantitative).
\end{abstract}

Keywords: possitive reinforcement and student discipline

\section{PENDAHULUAN}

Kebijaksanaan pemerintah mengenai pendidikan pada hakekatnya adalah sebagai usaha menyiapkan anak didik untuk menghadapi lingkungan hidup yang senantiasa mengalami perubahan dan pendidikan itu pada dasarnya bertujuan untuk meningkatkan kualitas hidup, kehidupan pribadi dan masyarakat. Pendidikan merupakan usaha dasar untuk mengembangkan kepribadian yang 


\section{FKIP Universitas PGRI Banyuwangi Seminar Nasional \\ Pendidikan Budaya dan Sejarah: "Dibalik Revitalisasi Budaya" \\ ISBN: 978-602-72362-7-1}

berlangsung di sekolah maupun di luar sekolah. Masalah yang dihadapi dalam pembangunan pendidikan adalah bagaimana meningkatkan mutu pendidikan, baik yang bersifat pengetahuan maupun sikap. Usaha pertama yang dilakukan oleh sekolah dalam pembinaan sikap yaitu melalui tata tertib sekolah. Hal ini mengakibatkan banyak kepentingan individu yang satu sama lainnya saling bertentangan, yang apabila tidak diatur maka akan menimbulkan suatu kekacauan.

Tata tertib sekolah merupakan salah satu bentuk aturan yang harus ditaati dan dilaksanakan oleh siswa, sebagai satu perwujudan kehidupan yang sadar akan hukum dan aturan. Lingkungan sekolah khususnya tingkat SMP yang beranggotakan remajaremaja yang sedang dalam masa transisi, sangat rentan sekali terhadap perilaku yang menyimpang. Oleh karena itu diperlukan suatu tata tertib (hukum atau aturan) yang harus diterapkan di sekolah yang bertujuan untuk membatasi setiap perilaku siswa. Tata tertib sekolah adalah rambu-rambu kehidupan bagi siswa dalam melaksanakan kehidupan dalam masyarakat sekolah. Lingkungan sekolah yang menjadi "hukum" nya adalah tata tertib sekolah.

Walaupun di beberapa sekolah telah menerapkan sistem poin untuk memberikan ancaman kepada siswa yang melanggar, namun siswa di sekolah akan tetap saja melanggar karena telah menjadi kebiasaan bagi mereka. Misalnya saja membolos, datang sekolah terlambat, berpakaian tidak lengkap, sampai merokok dan mencuri barang orang lain. Pelanggaran-pelanggaran ini disebabkan karena tidak ada kesadaran tentang arti dan pentingnya peraturan. Oleh karena itu, masalah pelanggaran yang dilakukan oleh siswa-siswi di sekolah jangan dianggap remeh, karena apabila ada satu orang siswa saja yang mempunyai potensi untuk melakukan pelanggaran, maka dijamin dengan beberapa kali dia melakukannya pasti berhasil mempengaruhi temannya.

Perilaku melanggar tata tertib semakin banyak terjadi di sekolah-sekolah. Perilaku melanggar tata tertib siswa juga terjadi di SMP Al-Irsyad Banyuwangi. Berdasarkan hasil studi pendahuluan dari keterangan guru BK, diketahui bahwa pada tahun ajaran 2017/2018 dari 14 kelas dari seluruh siswa dari kelas VII, VIII dan IX di SMP Al-Irsyad Banyuwangi yang melakukan palanggaran tata tertib, siswa yang mempunyai persentase melanggar tata tertib paling tinggi yaitu terdapat di kelas VIII. Siswa kelas VIII mengalami peningkatan pelanggaran tata tertib, jumlah siswa yang melanggar tata tertib setiap minggunya jika dihitung secara kasar mencapai 35 pelanggaran dengan pelanggaran bermacammacam. Sedangkan, setiap bulannya jumlah yang melanggar tata tertib dapat mencapai 60 kali pelanggaran. Adapun pelanggaran yang dilakukan berupa pelanggaran ringan dan pelanggaran berat. Sedangkan siswa kelas VIII mengalami pelanggaran berat berupa membolos dan berkelahi mencapai $50 \%$ (Menurut catatan anekdot sekolah). 


\section{FKIP Universitas PGRI Banyuwangi Seminar Nasional \\ Pendidikan Budaya dan Sejarah: "Dibalik Revitalisasi Budaya" \\ ISBN: 978-602-72362-7-1}

Melihat banyaknya dampak negatif kurangnya kedisiplinan yang muncul dari perilaku melanggar tata tertib sekolah, tentunya hal tersebut tidak dapat dibiarkan begitu saja. Perilaku tersebut juga tergolong perilaku yang tidak adaptif sehingga harus segera ditindak lanjuti. Menurut informasi dari guru BK SMP Al-Irsyad banyuwangi, penyebab dari perilaku melanggar tata tertib siswa sangat bermacam-macam, seperti adanya siswa yang datang terlambat, membolos dan berkelahi. Alasannya karena ikut-ikutan teman, malas dan hanya karena ingin mencari perhatian saja. Jika masalah tersebut dibiarkan begitu saja, dampak buruk akan semakin bertambah yaitu kurangnya kedisiplinan siswa, seperti membolos dan berkelahi, bahkan dapat menyebabkan siswa yang lain terpengaruh. Upaya yang sudah dilakukan guru BK adalah dengan memberikan poin serta hukuman atau memberi sanksi, akan tetapi masih saja banyak siswa yang melanggar. Hal tersebut penting diteliti untuk mengurangi tingkat perilaku melanggar tata tertib siswa di sekolah yang sebelumnya dianggap hal yang tidak begitu penting. Memanfaatkan layanan konseling kelompok behavior, maka siswa dapat mengupayakan penyelesaian masalahnya yang berkaitan dengan penurunan pelanggaran tata tertib siswa.

Setting sekolah, layanan konseling kelompok merupakan proses komunikasi dengan dinamika kelompok merupakan salah satu upaya yang digunakan dalam menanggulangi masalah pelanggaran tata tertib siswa. Layanan konseling kelompok merupakan cara yang amat baik untuk menangani konflik-konflik antar pribadi dan membantu individu-individu dalam pengembangan kemampuan pribadi mereka misalnya pengendalian diri, tenggang rasa \& teposeliro (Adhiputra, 2015: 23-24).

Konseling kelompok merupakan salah satu di antara beberapa jenis layanan bimbingan dan konseling yang dapat diandalkan. Konseling kelompok diharapkan membantu individu untuk berkembang sesuai dengan perkembangannya dan masalah yang dihadapi dapat terentaskan. Layanan konseling kelompok diberikan untuk mengurangi pelanggaran tata tertib siswa yang dilakukan dengan menggunakan konseling behavioral teknik positive reinforcement (penguatan positif).

Layanan konseling kelompok pendekatan behavioral dengan teknik positive reinforcement diberikan kepada siswa yang melakukan pelanggaran tata tertib. Positive reinforcement atau penguatan positif adalah "Reinforcement (pengukuhan) adalah stimulus yang menjadi konskuensi tingkah laku manusia. Apabila suatu respon atau tingkah laku telah dilakukan, dan sesudah itu dihadirkan suatu stimulus (benda atau kejadian) sebagai akibat atau konsekuensi dari tingkah laku tersebut, dan mengakibatkan tingkah laku tersebut sering muncul, meningkat atau diperkuat, maka peristiwa tersebut dinamai pengukuhan positif. 


\section{FKIP Universitas PGRI Banyuwangi Seminar Nasional \\ Pendidikan Budaya dan Sejarah: "Dibalik Revitalisasi Budaya" \\ ISBN: 978-602-72362-7-1}

Senyuman, belaian, perhatian, pelukan, aplaus, uang, benda, makanan dan sebagainya disebut positive reinforce, apabila kehadirannya meningkatkan kemungkinan berulangnya tingkah laku (dalam Jumarin, 2005: 88). Pada penelitian ini, teknik positive reinforcement diberikan dalam layanan konseling kelompok yaitu pada tahap kegiatan layanan konseling kelompok.

Berdasarkan uraian diatas peneliti tertarik untuk mengkaji tentang pelanggaran tata tertib siswa dan upaya untuk menurunkan perilaku tersebut. Maka penulis merumuskan uraian ini menjadi judul penelitian: "Pengaruh Konseling Kelompok Dengan Pendekatan Behavioral Teknik Positive Reinforcement Terhadap Penurunan Pelanggaran Tata Tertib Siswa Kelas VIII SMP Al-Irsyad Banyuwangi”.

Berdasarkan latar belakang di atas, maka yang akan menjadi rumusan masalah dalam penelitian ini yaitu, (1) Apakah konseling kelompok pendekatan behavioral dengan teknik positive reinforcement berpengaruh untuk menurunkan tingkat pelanggaran tata tertib siswa kelas VIII di SMP Al-Irsyad Banyuwangi? dan (2) Apakah terdapat perbedaan penurunan pelanggaran tata tertib antara kelompok eksperimen dan kelompok kontrol?

\section{KAJIAN LITERATUR DAN PENGEMBANGAN HIPOTESIS}

Shertzer dan Stones (dalam

Mappiare,2010:164) mendefinisikan konseling kelompok adalah "seorang konselor terlibat dalam suatu hubungan dengan sejumlah konseli dalam waktu yang sama". Sedangkan Ohlsen (dalam Winkel \& Hastuti, 2008) dalam bukunya Konseling Kelompok Perkembangan menyatakan bahwa konseling kelompok merupakan pengalaman terapeutik bagi orang-orang yang tidak mempunyanyi masalah emosional yang serius. Konseling kelompok ada hubungan antara konselor dengan anggota kelompok penuh rasa penerimaan, kepercayaan dan rasa aman. Lebih lanjut Hansen, dkk (dalam Prayitno 1999: 315) menegaskan bahwa layanan konseling kelompok merupakan cara yang amat baik untuk menangani konflik-konflik antar pribadi dan membantu individu-individu dalam pengembangan kemampuan pribadi mereka misalnya pengendalian diri, tenggang rasa \& teposeliro. ( Adhiputra Ngurah, 2015: 23-24).

Berdasarkan pemaparan diatas mengenai pengertian konseling kelompok, maka dapat disimpulkan bahwa konseling kelompok suatu proses antar pribadi yang dinamis antara konselor dengan satu atau lebih klien yang penuh rasa penerimaan, kepercayaan, rasa aman, serta untuk mengembangkan keberanian dan rasa kepercayaan pada diri sendiri.

Pendekatan behavioral menjelaskaan bahwa, perilaku, kognisi, dan perasaan bermasalah terbentuk karena dipelajari, oleh karenanya, dapat diubah melalui proses belajar juga. Perilaku yang dikatakan masalah adalah 


\section{FKIP Universitas PGRI Banyuwangi Seminar Nasional \\ Pendidikan Budaya dan Sejarah: "Dibalik Revitalisasi Budaya" \\ ISBN: 978-602-72362-7-1}

masalah itu sendiri bukan semata-mata gejala dari masalah (Rochman Natawidjaja, dalam Supriatna, 2015: 181). Secara sederhana behavioral dapat didefinisikan sebagai proses belajar, yang di dalam proses tersebut konselor menggunakan prosedur sistematis untuk membantu siswa menyempurnakan suatu perubahan khusus dalam perilaku ( Adhiputra, 2015: 154).

Reinforcement adalah konsekuensi yang memperkuat perilaku dan perilaku yang diikuti dengan reinfocement akan diulang pada waktu yang akan datang. Pemberian reinforcement positif mengacu pada teori operant conditioning dari Skiner yang memandang hadiah (reward) atau penguatan (reinforcement) sebagai unsur yang penting dalam kegiatan pembelajaran, karena dengan pemberian pengukuhan positif memberikan bukti salah satu bentuk perhatian tenaga pendidik pada peserta didik (Walgito, 2004:72) Menurut skinner (Corey, 2010: 89) reinforcement terbagi menjadi menjadi dua yaitu Reinforcemenet Positive dan Reinforcement negative. Positive Reinforcement yaitu sesuatu rangsangan (stimulus) yang memperkuat atau mendorong suatu respon (tingkah laku tertentu). Peneguhan positif ini berbentuk reward (ganjaran, hadiah, atau imbalan), baik secara verbal (kata-kata atau ucapan pujian), maupun secara non- verbal (isyarat, senyuman, hadiah berupa benda-benda dan makanan).

Contoh : pujian atau hadiah (sebagai rangsangan) yang diberikan kepada anak yang telah berhasil menulis huruf hijaiyah dengan baik, akan memperkuat, memperteguh atau mendorong anak untuk lebih giat lagi dalam belajarnya.

Reinforcement Negative, yaitu suatu rangsangan (stimulus) yang mendorong seseorang untuk menghindari respon tertentu yang konsekuensi atau dampaknya tidak memuaskan (menyakitkan atau tidak menyenangkan). Peneguhan negatif ini bentuknya berupa hukuman atau pengalaman yang tidak menyenangkan.

Contoh : seorang anak yang dihukum oleh guru karena terlambat menyerahkan tugas akan berusaha untuk tidak mengulang lagi perbuatannya tersebut. Hukuman dari guru merupakan peneguhan negatif, karena mendorong anak untuk tidak mengulang kembali kesalahannya, yaitu terlambat menyerahkan tugas (sebagai respon atau perbuatan yang dampaknya tidak menyenangkan sama dengan mendapat hukuman).

Satu cara untuk mengingat perbedaan antara penguatan positif dan penguatan negatif adalah dalam penguatan positif ada sesuatu yang ditambahkan atau diperoleh. Penguatan negatif, ada sesuatu yang dikurangi atau di hilangkan adalah mudah mengacaukan penguatan negatif dengan hukuman. Agar istilah ini tidak rancu, ingat bahwa penguatan negatif meningkatkan probabilitas terjadinya suatu prilaku, sedangkan hukuman menurunkan probabilitas terjadinya perilaku. Penelitian ini menggunakan teknik positive 


\section{FKIP Universitas PGRI Banyuwangi Seminar Nasional Pendidikan Budaya dan Sejarah: "Dibalik Revitalisasi Budaya" ISBN: 978-602-72362-7-1}

reinforcement adalah memberikan penguatan yang menyenangkan setelah tingkah laku yang diinginkan ditampilkan yang bertujuan agar tingkah laku yang diinginkan cenderung akan diulang, meningkat dan menetap di masa akan datang ( dalam Komalasari dkk, 2011: 161)

Secara umum tata tertib sekolah dapat diartikan sebagai ikatan atau aturan yang harus dipatuhi setiap warga sekolah tempat berlangsungnya proses belajar mengajar. Pelaksanaan tata tertib sekolah akan dapat berjalan dengan baik jika guru, aparat sekolah dan siswa telah saling mendukung terhadap tata tertib sekolah itu sendiri, kurangnya dukungan dari siswa akan mengakibatkan kurang berartinya tata tertib sekolah yang diterapkan di sekolah.

Menurut Suparlan ( 2009: 145 ), tata tertib adalah sekumpulan aturan-aturan yang ditujukan oleh semua komponen di dalam suatu lembaga atau organisasi agar selalu tunduk dan melaksanakan apa yang telah ditetapkan. Sedangkan menurut (Disdikpora, 2014: 282a) Tata Tertib Peserta Didik adalah segala ketentuan yang ditetapkan oleh sekolah untuk ditaati dan dilaksanakan oleh peserta didik yang bertujuan agar kegiatan belajar mengajar dapat berlangsung efektif. Di lingkungan sekolah, tata tertib diperlukan untuk menciptakan kehidupan sekolah yang tertib, tentram, kondusif dan penuh dengan kedisiplinan. Sehingga keberhasilan proses belajar mengajar dapat terlaksana dengan baik.

Paparan diatas, memberi kesimpulan bahwa perilaku disiplin tata tertib di sekolah adalah perilaku yang sesuai dengan peraturan dan norma yang ditetapkan oleh pihak sekolah untuk membentuk rasa tanggungjawab dalam berperilaku dilingkungan sekolah.

Hipotesis dari penelitian ini adalah (1) Konseling kelompok behavioral teknik positive reinforcement berpengaruh terhadap penurunan pelanggaran tata tertib siswa kelas VIII di SMP Al-Irsyad Banyuwangi dan (2) Terdapat perbedaan pengaruh terhadap penurunan tata tertib siswa antara kelompok eksperimen dan kelompok kontrol.

\section{METODE PENELITIAN}

Populasi penelitian ini adalah seluruh siswa kelas VIII di SMP Al-Irsyad Banyuwangi pada tahun ajaran 2017/2018 yang berjumlah 136 orang. Sampel diambil menggunakan teknik purposive sampling, diperoleh 20 orang sebagai sampel, yang kemudian dalam penelitian ini dibagi menjadi dua kelompok sebagai kelompok eksperimen dan satu menjadi kelompok kontrol.

Data pada penelitian ini dikumpulkan menggunakan dua data, yaitu Utama dan Pelangkap. Metode pengumpulan Data Utama adalah Kuesioner pelanggaran tata tertib sebanyak 30 butir soal, sedangkan metode pengumpulan data pelangkap adalah Observasi dan wawancara sebanyak 5 butir soal. Hasil analisis data pada uji instrumen memberikan harga Alpha Cronbach untuk kuesioner pelanggaran tata tertib dengan kriteria yang telah ditentukan. 


\section{FKIP Universitas PGRI Banyuwangi Seminar Nasional \\ Pendidikan Budaya dan Sejarah: "Dibalik Revitalisasi Budaya" \\ ISBN: 978-602-72362-7-1}

Analisis data yang digunakan meliputi teknik analisis dekskriptif Data instrumen pelanggaran tata tertib siswa dianalisis secara deskriptif dan dinyatakan dengan jenjang kualifikasi. Jenjang kualifikasi di kategorikan berdasarkan skor rata-rata $(\bar{X})$, mean ideal $\left(\mathrm{SD}_{\mathrm{i}}\right)$, dan standar deviasi ideal $\left(\mathrm{SD}_{\mathrm{i}}\right)$. Setelah melakukan analisis deskriptif dilakukan uji prasyarat analisis yang terdiri dari uji normalitas dan uji homogenitas.

Uji normalitas sebaran data dilakukan untuk meyakinkan bahwa data yang dihasilkan dalam penelitian benar-benar berdistribusi normal, sehingga uji hipotesis dapat dilakukan. Uji normalitas sebaran data menggunakan statistik Kolmogorov-Smirnov Test dan Shapiro Wilk Test (Candiasa, 2004). Uji ini dapat dilakukan dengan memanfaatkan bantuan SPSS 16.0 for Windows. Kriteria pengujiannya adalah data memiliki sebaran distribusi normal jika angka signifikansi yang diperoleh lebih besar dari $p>0,05$ dan dalam hal lain sebaran tidak berdistribusi normal.

Uji homogenitas digunakan untuk mengetahui apakah kelompok- kelompok sampel berasal dari polulasi yang sama. Kesamaan asal sampel ini dibuktikan dengan adanya kesamaan varians kelompokkelompok yang membentuk sampel tersebut. Jika tidak ada perbedaan varians antara kelompok- kelompok sampel ini berarti bahwa kelompok tersebut bersifat homogen, sehingga dapat disimpulkan bahwa kelompok sampel tersebut berasal dari populasi yang sama (Sugiyono, 2010). Uji homogenitas varians antar kelompok menggunakan Levene's Test of Equality of Error Variance (Candiasa, 2004). Uji ini dapat dilakukan dengan memanfaatkan bantuan SPPS 16.0 for Windows. Pedoman yang digunakan untuk menetapkan homogenitas, yaitu menetapkan taraf signifikansi $(\alpha=0.05), \quad(2)$ jika signifikansi yang diperoleh $>\alpha$, maka varians setiap sampel sama (homogen), (3) jika signifikansi yang diperoleh $<\alpha$, maka varians setiap sampel tidak sama (tidak homogen).

Bila uji prasyarat telah memenuhi kriteria maka dilakukan uji hipotesis. Tujuan dari analisis data ini adalah mengungkapkan apa yang ingin diketahui dari penelitian ini. Dalam menganalisis data yang diperoleh selama melakukan penelitian, penulis menggunakan dua analisis statistik, antara lain (1) analisis statistik correlated data/paired sampel t-test dan (2) analisis statistik uncorrelated data/independent sampel t-test.

Dasar pengambilan keputusannya adalah (1) Jika t hitung > t tabel, maka $\mathrm{H}_{0}$ ditolak dan (2) Jika t hitung $<\mathrm{t}$ tabel, maka $\mathrm{H}_{0} \quad$ diterima. Berdasarkan nilai probabilitasnya adalah (1) Jika probabilitas > 0,05 maka $\mathrm{H}_{0}$ diterima dan (2) Jika probabilitas $<0,05$ maka $\mathrm{H}_{0}$ ditolak.

\section{RANCANGAN PENELITIAN}

Rancangan control group design dipilih dengan pertimbangan bahwa dalam eksperimen semu, tidak memungkinkan untuk merandom subjek dalam kelompok populasi 


\section{FKIP Universitas PGRI Banyuwangi Seminar Nasional Pendidikan Budaya dan Sejarah: "Dibalik Revitalisasi Budaya" ISBN: 978-602-72362-7-1}

secara utuh. Selanjutnya pretest dan posttest berarti memberikan tes kepada subjek sebelum dan setelah perlakuan diberikan pada masingmasing kelompok. Rancangan ini dipilih karena penelitian ini merupakan penelitian terapeutik untuk mengetahui efektivitas atau pengaruh perlakuan terhadap variabel terikat. Artinya rancangan pretest dan posttest digunakan untuk mengetahui Pengaruh Konseling Kelompok Behavioral Teknik Positive Reinforcement Terhadap Penurunan Pelanggaran Tata Tertib Siswa Kelas VIII SMP Al-Irsyad Banyuwangi.

$\begin{array}{llll}\mathrm{E} & \mathrm{O}_{1} & \mathrm{X} & \mathrm{O}_{2}\end{array}$<smiles>[R]O[Na]</smiles>

(Sumber: Dantes, 2012:97)

\section{Gambar 03. Desain Non Equivalent Pretest-}

\section{Posttest Control Group}

$\mathrm{X} \quad$ : Konseling behavioral dengan teknik positive reinforcement

- $\quad$ : Konseling kelompok tanpa teknik khusus

$\mathrm{O}_{1}$ : Pengamatan awal, berupa pre-test sebelum diberikan perlakuan.

$\mathrm{O}_{2} \quad$ : Pengamatan akhir, yaitu pemberian post-test setelah diberikan perlakuan

\section{KESIMPULAN}

Pada penelitian ini, teknik positive reinforcement diberikan dalam layanan konseling kelompok yaitu pada tahap kegiatan layanan konseling kelompok. Penulis merasa tertarik untuk mengkaji tentang pelanggaran tata tertib siswa dan upaya untuk menurunkan perilaku tersebut. Sehingga diperoleh rumusan masalah dalam penelitian sebagai berikut: (1) Apakah konseling kelompok pendekatan behavioral dengan teknik positive reinforcement berpengaruh untuk menurunkan tingkat pelanggaran tata tertib siswa kelas VIII di SMP Al-Irsyad Banyuwangi? dan (2) Apakah terdapat perbedaan penurunan pelanggaran tata tertib antara kelompok eksperimen dan kelompok kontrol?.

Menurut skinner (Corey, 2010: 89), Positive Reinforcement yaitu sesuatu rangsangan (stimulus) yang memperkuat atau mendorong suatu respon (tingkah laku tertentu). Menurut Suparlan ( 2009: 145 ), tata tertib adalah sekumpulan aturan-aturan yang ditujukan oleh semua komponen di dalam suatu lembaga atau organisasi agar selalu tunduk dan melaksanakan apa yang telah ditetapkan.

Populasi penelitian ini adalah seluruh siswa kelas VIII di SMP Al-Irsyad Banyuwangi pada tahun ajaran 2017/2018 yang berjumlah 136 orang. Sampel diambil menggunakan teknik purposive sampling. Hasil analisis data pada uji instrumen memberikan harga Alpha Cronbach untuk kuesioner pelanggaran tata tertib dengan kriteria yang telah ditentukan.

\section{REFERENSI}


ISBN: 978-602-72362-7-1

Adhiputra, A.A. Ngurah. 2014. Konseling Kelompok Perspektif Teori Dan Aplikasi. Yogyakarta: Media Akademi.

Dantes, Nyoman. 2012. Metode Penelitian. Yogyakarta: Penerbit Andi.

Dantes, Nyoman. 2014. Analisis dan Desain Eksperimen. Singaraja: Universitas Pendidikan Ganesha.

Komalasari, Gantina dkk. 2011. Teori dan Teknik Konseling. Jakarta: PT. Indeks.

Sunarata, Kadek. 2010. Panduan Memimpin Kelompok dalam Konseling Kelompok. Singaraja: Universitas Pendidikan Ganesha Singaraja. 